\title{
Inflammation, genetics, and longevity: further studies on the protective effects in men of IL-10-1082 promoter SNP and its interaction with TNF- $a-308$ promoter SNP
}

\author{
D Lio, L Scola, A Crivello, G Colonna-Romano, G Candore, M Bonafè, L Cavallone, \\ F Marchegiani, F Olivieri, C Franceschi, C Caruso
}

J Med Genet 2003;40:296-299

A geing is associated with chronic, low grade inflammatory activity leading to long term tissue damage, and systemic chronic inflammation has been found to be related to mortality risk from all causes in older persons. ${ }^{1}$ Also, the genetic constitution of the organism interacting with systemic inflammation may cause defined organ specific illnesses. Thus, age related diseases such as Alzheimer's disease $(\mathrm{AD})$, Parkinson's disease, atherosclerosis, type 2 diabetes, sarcopenia, and osteoporosis, are initiated or worsened by systemic inflammation, suggesting the critical importance of unregulated systemic inflammation in the shortening of survival in humans. ${ }^{1-3}$ Accordingly, proinflammatory cytokines are believed to play a pathogenetic role in age related diseases, and genetic variations located within their promoter regions have been shown to influence the susceptibility to age related diseases, by increasing gene transcription and therefore cytokine production. ${ }^{34}$

Conversely, genetic variations determining increased production of anti-inflammatory cytokines or decreased production of proinflammatory cytokines have been shown to be associated with successful ageing, suggesting a role for the control of the inflammatory state in the attainment of longevity. As recently reported, the distribution of $+874 \mathrm{~T} \rightarrow \mathrm{A}$ interferon(IFN)- $\gamma^{5} \quad-174 \mathrm{C} \rightarrow \mathrm{G} \quad$ IL- $6,{ }^{6}$ and $\quad-1082 \mathrm{G} \rightarrow \mathrm{A}$ interleukin(IL)- $10^{7}$ single nucleotide polymorphisms (SNPs) has been shown to be different in centenarians than in younger people..$^{5-7}$ The $+874 \mathrm{~T}$ allele, involved in high production of the proinflammatory cytokine IFN- $\gamma$, was found less frequently in centenarian women than in control women. ${ }^{5}$ Also, the proportion of subjects homozygous for the G allele at the $-174 I L-6$ locus, characterised by high serum levels of the proinflammatory cytokine IL-6, was significantly decreased in centenarian men. ${ }^{6}$ Conversely, the presence of the -1082 GG genotype, suggested to be associated with high production of the anti-inflammatory cytokine IL-10, was significantly increased in centenarian men in comparison with younger male subjects. ${ }^{7}$ These gender related effects are difficult to explain. However, it is well known that men and women may follow different strategies to reach longevity and that the number of centenarian women always outnumber centenarian men, the ratio between women and men ranging from 4/1 to $7 / 1$, with the exception of Sardinia. ${ }^{89}$

It is rather simplistic to examine the influence of a single cytokine in isolation. In fact, cytokines interact in networks in which the functions of one cytokine are modified, modulated, or substituted by another one(s). ${ }^{4}$ In particular, IL-10 and tumour necrosis factor (TNF- $\alpha$ ), a classical proinflammatory cytokine, have complex and opposing roles, ${ }^{11}{ }^{11}$ and an autoregulatory loop appears to exist in which TNF- $\alpha$ stimulates IL-10 production which, in turn, reduces TNF- $\alpha$ synthesis. ${ }^{12}{ }^{13}$ Furthermore, their synergistic role in the control of immune-inflammatory responses has been hypothesised. ${ }^{14}$ To gain further insight into the relation between inflamma-

\section{Key points}

- Many aspects of ageing involve inflammatory processes. We evaluated the association with longevity of alleles of IL-10 and TNF-a, known to have opposite functions in inflammatory reactions, IL-10 acting predominantly as an anti-inflammatory and TNF- $\alpha$ as a proinflammatory factor.

- The number of male centenarians homozygous for the $-1082 \mathrm{G}$ genotype, suggested to be associated with high IL-10 production, was significantly increased in comparison with younger control subjects. No significant differences were observed between women and controls. The genotypic frequencies of the TNF-a promoter SNPs 308G and 308A, suggested to be associated with low and high TNF- $\alpha$ production respectively, were not significantly different between centenarians and controls. The evaluation of combined IL-10 and TNF-a genotypes showed that there was a significant increase of the "anti-inflammatory" (IL-10 -1082GG) TNF- $a-308 G G)$ genotype in centenarian men over controls.

- Inflammatory markers predict disability and mortality in elderly cohorts and a persistent inflammatory state has been proposed to be involved in the causal pathway of certain age related chronic conditions. Thus, it is intriguing that the possession of an "anti-inflammatory" genotype is significantly increased in male centenarians.

tory cytokines and longevity, we investigated the frequency of the $-1082 \mathrm{G} \rightarrow \mathrm{A} I L-10$ promoter SNP in a larger cohort of 72 centenarian men, including 25 typed in a previous study, and the interaction of this polymorphism with $-308 \mathrm{~A} \rightarrow \mathrm{G} T N F-\alpha$ SNP.

\section{MATERIALS AND METHODS}

DNA samples were obtained from 72 unrelated centenarian men ( 25 of whom were part of a previous study) ${ }^{7}$ and 102 centenarian women from central and southern Italy. DNA samples from healthy unrelated controls (115 men and 112 women, aged 22-60 years), matched for geographical origin, were also collected. Written informed consent for enrolment in the study and for personal data management was obtained from all the subjects according to Italian laws.

Blood specimens were collected in tripotassium EDTA sterile tubes and immediately stored at $-70^{\circ} \mathrm{C}$. Genomic DNA extraction was carried out and DNA stored at $-20^{\circ} \mathrm{C}$ for the $I L-10$ and TNF- $\alpha$ gene analysis. Complete linkage of allele $-819 \mathrm{C}$ with allele $-592 \mathrm{C}$ and of allele $-819 \mathrm{~T}$ with allele $-592 \mathrm{~A}$, 
Table 1 Genotypic frequencies for $1082 \mathrm{G} \rightarrow \mathrm{A}$ IL-10 promoter gene SNP and for 308G $\rightarrow$ A TNF-a promoter gene SNP in 115 controls and in 72 centenarian men

\begin{tabular}{lcc}
\hline & Controls (\%) & Centenarians (\%) \\
\hline-1082 IL-10 & $19(16)$ & $5(7)$ \\
AA & $64(56)$ & $34(47)$ \\
AG & $32(28)$ & $33(46)$ \\
GG 308 TNF-a & $1(1)$ & $1(1)$ \\
AA & $31(27)$ & $15(21)$ \\
AG & $83(72)$ & $56(78)$ \\
GG &
\end{tabular}

All groups were in Hardy Weinberg equilibrium ( $p>0.05$ ). A significantly different distribution of IL-10 genotypes was observed between controls and centenarians ( $p=0.019$ by $\chi^{2}$ test). Similarly, the frequency of SNP $-1082 \mathrm{G}$ was significantly increased in centenarians over controls $\left(0.69 \vee 0.56, p=0.01\right.$ by $\chi^{2}$ test). It is noteworthy that this significant difference was observed both in the previous sample of 25 centenarians $\left(0.76 \vee 0.56, p=0.012\right.$ by $\chi^{2}$ test) and in the new sample of 47 centenarians $(0.66 \vee 0.56, p=$ 0.035 by $\chi^{2}$ test). No significant different distribution of TNF- $a-308$ genotypes was observed between controls and centenarians by $\chi^{2}$ test and the frequency of SNPs $-308 \mathrm{G} \rightarrow \mathrm{A}$ was not significantly different between centenarians and controls by $\chi^{2}$ test.

and the presence of only three different allele combinations, $-1082 \mathrm{G},-819 \mathrm{C}$, and $-592 \mathrm{C}$ GCC, ACC, and ATA, are characteristic of the $I L-10$ polymorphisms in white populations. ${ }^{15}$ In the previous study, only -1082 SNP was shown to be associated with longevity, so in the present study we limited ourselves to the analysis of the $-1082 \mathrm{G} \rightarrow \mathrm{A}$ SNP. This biallelic polymorphism (GeneBank accession number: 790448) was identified using ARMS-PCR as previously described. ${ }^{7}$ The biallelic polymorphisms at $-308(\mathrm{G} \rightarrow \mathrm{A})$ (GeneBank Accession number CR941560) of the TNF- $\alpha$ gene was identified also using the ARMS-PCR method as previously described. ${ }^{16}$ Allele typing was confirmed according to Wilson et al. ${ }^{17}$

TNF- $\alpha$ and $I L-10$ genotypic and allelic frequencies were evaluated by gene count. The data were tested for the goodness of fit between the observed and expected genotype values $\left(\chi^{2}\right.$ test $)$ and their fit to Hardy-Weinberg equilibrium. $\chi^{2}$ tests ( $3 \times 2$ tables or $2 \times 2$ tables) were performed to calculate significantly different genotype or allele distributions between centenarians and controls.

\section{RESULTS}

Table 1 shows the frequency of homozygous and heterozygous genotypes for $-1082 \mathrm{G} \rightarrow \mathrm{A} I L-10 \mathrm{SNP}$ and for $-308 \mathrm{G} \rightarrow \mathrm{A}$ TNF- $\alpha$ in our sample of Italian centenarian men and sex matched controls. The number of centenarians homozygous for the $-1082 \mathrm{G}$ genotype was significantly increased in this cohort of centenarian men in comparison with younger control subjects $(p=0.019)$. Accordingly, the SNP distribution between centenarians and controls was significantly different, with the $-1082 \mathrm{G}$ allele increased in centenarians $(0.69 v 0.56$, $\mathrm{p}=0.01$ by $\chi^{2}$ test). As already reported, ${ }^{7}$ no significant differences were observed in women, between centenarians and controls $\left(-1082 \mathrm{G}, 0.62 \vee 0.59, \mathrm{p}=\mathrm{NS}\right.$ by $\chi^{2}$ test $)$. The genotypic frequencies of the TNF- $\alpha$ promoter SNP of centenarian and control men were not significantly different. Accordingly, the frequency of SNP $-308 \mathrm{G} \rightarrow$ A was not significantly different between centenarians and controls $\left(\chi^{2}\right.$ test). The same was observed in the group of centenarian women $(-308 \mathrm{G}, 0.88 \mathrm{v}$ $0.79, \mathrm{p}=\mathrm{NS}$ by $\chi^{2}$ test $)$.

As far as cytokine production is concerned, the $I L-10$ and $T N F-\alpha$ polymorphisms considered are functionally important. Thus, centenarians and controls were classified into four groups, as shown in table 2 . We compared the frequency of the genotype "low TNF- $\alpha$ and high $I L-10^{\prime}$ producer, "antiinflammatory genotype ${ }^{\prime 14}$ with the other genotypes in centenarian and control men. There was a significant increase of this "anti-inflammatory genotype" in centenarians over controls ( $36 \%$ v $21 \% ; \mathrm{p}=0.038$ by $\chi^{2}$ test). In women, there were no significant differences in the distribution of the "functional" genotypes between centenarians and younger subjects $\left(32 \% \vee 21, \mathrm{p}=\mathrm{NS}\right.$ by $\chi^{2}$ test $)$.

\section{DISCUSSION}

The main result of this study was that the $I L-10$ gene SNP $-1082 \mathrm{G} \rightarrow \mathrm{A}$ had significant influence on the attainment of longevity in men, both separately and in association with the $T N F-\alpha$ gene SNP $-3082 \mathrm{~A} \rightarrow \mathrm{G}$. It is noteworthy that the $I L-10$ frequency was analysed in a large cohort of male centenarians, thus validating our preliminary results on a smaller sample of centenarian men. ${ }^{7}$ This result is remarkable, taking into account that centenarian men are relatively rare, being many fewer than centenarian women. ${ }^{8}$

IL-10 and TNF- $\alpha$ are cytokines, which have complex and predominantly opposing roles in the inflammatory responses. ${ }^{10}{ }^{11}$ In fact, the principal routine function of IL-10 is to limit and ultimately terminate inflammatory responses, ${ }^{10}$ whereas TNF- $\alpha$ determines strength, effectiveness, and duration of local and systemic inflammatory reactions. ${ }^{11}$ Stimulation of human blood samples with bacterial lipopolysaccharide showed large interperson variations of IL-10 and TNF- $\alpha$ production, suggesting a genetic component of approximately $75 \%$ and $60 \%$, respectively. ${ }^{18}$ Interperson differences in the regulation of IL-10 and TNF- $\alpha$ production may be critical with respect to the final outcome of an inflammatory response, that is within physiological limits or pathological ones. ${ }^{18}$ Several polymorphisms located close to or within the $I L-10$ and TNF- $\alpha$ genes have been shown to be associated with transcription levels. The best documented of these polymorphisms are the $I L-10$ gene promoter polymorphisms $-1082 \mathrm{G} \rightarrow \mathrm{A}^{716{ }^{19-23}}$ and a $\mathrm{G} \rightarrow \mathrm{A}$ transition at position -308 in the promoter region of TNF- $\alpha .{ }^{11}{ }^{132425}$ In the presence of allele -1082A, stimulation of lymphocytes with concanavalin A resulted in lower IL-10 production than in allele $-1082 \mathrm{~A}$ negative cells. ${ }^{1421}$ Also, the effects of this allelic promoter region difference (relative to the transcription start site) on $I L-10$ gene activation have been confirmed in reporter gene assays. ${ }^{20}$ Concerning $T N F-\alpha$, there are also data relating the rare $-308 \mathrm{~A}$ allele to a higher transcriptional activity than the common $-308 \mathrm{G}$ allele, ${ }^{11} 132425$ although a lack of such an association has also been reported in non-white populations, depending on the HLA ancestral haplotype carrying this SNP. ${ }^{124}$ However, the functional relevance of these SNPs has been shown by their involvement in determining susceptibility to immune-inflammatory diseases (for $I L-10-1082 \mathrm{G} \rightarrow \mathrm{A}_{1}^{14} 2026-35$ for $T N F-\alpha^{11-132425} 36-42$ ).

Table 2 Functional IL-10/TNF-a genotypes

\begin{tabular}{lll}
\hline & TNF- $a-308 \mathrm{~A}$ carrier (A/A, & TNF-a-308G/G \\
\hline A/G) & Low IL-10, high TNF- $\alpha$ & Low IL-10, low TNF- $\alpha$ \\
\hline IL-10-1082A carrier (A/A, A/G) & High IL-10, high TNF- $\alpha$ & High IL-10, low TNF- $\alpha$ \\
\hline L-10-1082G/G &
\end{tabular}

IL-10-1082A carriers are classified as "low IL-10 producers"; IL-10-1082GG homozygotes are classified as "high IL-10 producers"; TNF- $a-308 \mathrm{~A}$ carriers are classified as "high TNF producers"; TNF- $a-308 \mathrm{GG}$ homozygotes are classified as "low TNF producers". For references, see text. 
The isolated assessment of cytokine genotypes may be misleading without considering other interacting cytokines. In vivo control of TNF- $\alpha$ synthesis is complex and downregulated by anti-inflammatory cytokines including IL-10. ${ }^{12}$ The potential biological importance of this finding was highlighted by a recent study showing a strong association between the combined low $I L-10 /$ high TNF- $\alpha$ genotype and early graft rejection in heart transplant recipients. ${ }^{14}$ Other recent studies have shown the complementary importance of IL-10 and TNF- $\alpha$ in patients with bacterial sepsis and have indicated an increased mortality in patients with a high plasma IL-10 to TNF- $\alpha$ ratio, that is, in patients with an antiinflammatory phenotype (unfortunately in this study patients were not genotyped). ${ }^{43}$ Thus, in the light of different pathophysiological situations, it is difficult to assume a beneficial or detrimental effect of $I L-10 / T N F-\alpha$ genotypes separately or in combination. So, inflammatory genotypes may be both friends and enemies. In fact, they are an important and necessary part of the normal host responses to pathogens, but the overproduction of inflammatory cytokines might cause immune-inflammatory diseases and eventually death. In particular, an anti-inflammatory genotype might be highly advantageous in the last decades of life owing to the chronic proinflammatory status, which develops in all the subjects with age. This phenomenon that we called inflamm-ageing is more evident in men than in women. ${ }^{14}$ This could be a possible explanation for the higher frequency of the antiinflammatory genotype we found in very old male subjects. We can also predict that the presence of the "high $I L-10 /$ low $T N F-\alpha$ " genotype could be favourable in protecting against age related diseases such as AD and in elderly stroke. ${ }^{35} 4546$

Finally, we would like to stress that our study has a number of possible limitations. Since this study was performed with Italian centenarians, we do not know whether the results can be extended to populations of other ethnic origins. Notably, in a Finnish population, $I L-10$ and TNF- $\alpha$ promoter allele and haplotype frequencies were not different between nonagenarians and controls. ${ }^{47}$ Moreover, no significant association between polymorphisms of some cytokines and longevity has been found in the Sardinian population.$^{48}$ On the whole, these findings suggest that cytokine/longevity associations might have a population specific component, being affected by the population specific gene pool as well as by gene-environment interaction. Another limitation of the study was the lack of data regarding plasma levels of IL-10 and TNF- $\alpha$, but the functional relevance of the polymorphisms studied is well known (see above). Besides, it may be argued that a Bonferroni type adjustment should be performed to correct for the testing of multiple polymorphisms. If this correction is carried out, none of the polymorphisms would have been significantly associated. However, this correction is too stringent and has the potential to ignore important observations ${ }^{49}$ and, in any case, for studies on centenarians the number of cases is very hard to increase.

However, inflammatory markers predict disability and mortality in elderly cohorts and a persistent inflammatory state has been proposed to be involved in the causal pathway of certain age related chronic conditions. ${ }^{1350}$ Thus, it is intriguing that the possession of an "anti-inflammatory" genotype is significantly increased in male centenarians.

\section{ACKNOWLEDGEMENTS}

The "Gruppo di Studio sull'immunosenescenza" coordinated by Professor C Caruso is funded by grants from the Italian Ministry of Education, University and Research (MIUR) (ex 40\%, to CC and DL; ex $60 \%$ to CC, DL, GC, and GCR) and from the Italian Ministry of Health Projects "Immunological parameters age-related" and "Pharmacogenomics of Alzheimer's disease". The collaboration between this group and the Istituto Nazionale di Riposo e Cura per Anziani was enhanced by a cooperation contract (Longevity and elderly disability biological markers) and by the EU thematic network programme ImAginE
(QLK6-CT-1999-02031). Professor C Franceschi was funded by MIUR Rome (ex 40\%), Ministry of Health projects (1998 and 2001 "Chronic diseases prevention in ageing: the model of centenarians" and "Biological and genetic markers of successful and unsuccessful ageing"). LC is a PhD student in Pathobiology.

\section{Authors' affiliations}

D Lio, L Scola, A Crivello, G Colonna-Romano, G Candore,

L Cavallone, C Caruso, Gruppo di Studio dell'Immunosenescenza,

Dipartimento di Biopatologia e Metodologie Biomediche, Università di Palermo, Corso Tukory 21190134 , Palermo, Italy

M Bonafè, C Franceschi, Dipartimento di Patologia Sperimentale,

Università di Bologna, Bologna, Italy

L Cavallone, F Marchegiani, F Olivieri, C Franceschi, Istituto

Nazionale di Riposo e Cura per Anziani di Ancona, Ancona, Italy

Correspondence to: Professor C Caruso, Gruppo di Studio

dell'Immunosenescenza, Dipartimento di Biopatologia e Metodologie

Biomediche, Corso Tukory 21 1, 90134 Palermo, Italy; marcoc@unipa.it

\section{REFERENCES}

1 Bruunsgaard $\mathbf{H}$, Pedersen $M$, Pedersen BK. Aging and proinflammatory cytokines. Curr Opin Hematol $2001 ; 8: 131-6$

2 Brod SA. Unregulated inflammation shortens human functional longevity. Inflamm Res 2000;49:561-70.

3 Pawelec G, Barnett Y, Forsey R, Frasca D, Globerson A, McLeod J, Caruso C, Franceschi C, Fulop T, Gupta S, Mariani E, Mocchegiani E, Solana R. T cells and aging, January 2002 update. Front Biosci 2002; 7: 1056-83

4 Bidwell J, Keen L, Gallagher G, Kimberly R, Huizinga T, McDermott MF, Oksenberg J, McNicholl J, Pociot F, Hardt C, D'Alfonso S. Cytokine gene polymorphism in human disease: on-line databases. Genes Immunity 1999;1:3-19.

5 Lio D, Scola L, Crivello A, Bonafè M, Franceschi C, Olivieri F, Colonna-Romano G, Candore G, Caruso C. Allele frequencies of $+874 \mathrm{~T} \rightarrow \mathrm{A}$ single nucleotide polymorphism at the first intron of interferon- $\gamma$ gene in a group of Italian centenarians. Exp Gerontol 2002;37:317-21.

6 Bonafe M, Olivieri F, Cavallone L, Giovagnetti S, Marchegiani F, Cardelli M, Pieri C, Marra M, Antonicelli R, Lisa R, Rizzo MR, Paolisso $G$, Monti D, Franceschi C. A gender-dependent genetic predisposition to produce high levels of IL-6 is detrimental for longevity. Eur J Immunol 2001;31:2357-61.

7 Lio D, Scola L, Crivello A, Colonna-Romano G, Candore G, Bonafè M, Cavallone L, Franceschi C, Caruso C. Gender specific association between -1082 IL-10 promoter polymorphism and longevity. Genes Immunity 2002;3:30-3.

8 Franceschi C, Motta L, Valensin S, Rapisarda R, Franzone A, Berardelli M, Motta M, Monti D, Bonafe M, Ferrucci L, Deiana L, Pes GM, Carru C Desole MS, Barbi C, Sartoni G, Gemelli C, Lescai F, Olivieri F, Marchegiani F, Cardelli M, Cavallone L, Gueresi P, Cossarizza A Troiano L, Pini G, Sansoni P, Passeri G, Lisa R, Spazzafumo L, Amadio L, Giunta S, Stecconi R, Morresi R, Viticchi C, Mattace R, De Benedictis G, Baggio G. Do men and women follow different trajectories to reach extreme longevity? Italian Multicenter Study on Centenarians (IMUSCE). Aging (Milano) 2000;12:77-84.

9 Deiana L, Ferrucci L, Pes GM, Carru C, Delitala G, Ganau A, Mariotti S, Nieddu A, Pettinato S, Putzu P, Franceschi C, Baggio G. AKEntAnnos. The Sardinia Study of Extreme Longevity. Aging (Milano) 1999; 11:142-9.

10 Moore KW, de Waal Malefyt R, Coffman RL, O'Garra A. Interleukin-10 and the interleukin-10 receptor. Annu Rev Immunol 2001:19:683-765.

11 Makhatadze NJ. Tumor necrosis factor locus: genetic organisation and biological implications. Hum Immunol 1998;59:571-9

12 Candore G, Lio D, Colonna Romano G, Caruso C. Pathogenesis of autoimmune diseases associated with 8.1 ancestral haplotype: effect of multiple gene interactions. Autoimmunity Rev 2002;1:29-35.

13 Lio D, Candore G, Colombo A, Colonna Romano G, Gervasi F, Marino $V$, Scola L, Caruso C. A genetically determined high setting of TNF- $\alpha$ influences immunological parameters of HLA-B8, DR3 positive subjects: implications for autoimmunity. Hum Immunol 2001:62:705-13.

14 Hutchinson IV, Pravica V, Hajeer A, Sinnott PJ. Identification of high and low responders to allografts. Rev Immunogenet 1999;1:323-33.

15 Eskdale J, Keijsers V, Huizinga T, Gallagher G. Microsatellite alleles and single nucleotide polymorphisms (SNP) combine to form four major haplotype families at the human interleukin-10 (IL-10) locus. Genes Immunity 1999;1:151-5.

16 Cataldo F, Lio D, Marino V, Scola L, Crivello A, Mulè AM, Corazza GR. Cytokine genotyping (TNF and II-10) in patients with celiac disease and selective IgA deficiency. Am J Gastroenterology (in press).

17 Wilson AG, di Giovine FS, Blakemore Al, Duff GW. Single base polymorphism in the human tumour necrosis factor alpha (TNF alpha) gene detectable by $\mathrm{Ncol}$ restriction of PCR product. Hum Mol Genet 1992;1:353

18 Westendorp RG, Langermans JA, Huizinga TW, Verweii CL, Sturk A Genetic influence on cytokine production and fatal meningococcal disease. Lancet 1997;349:170-3. 
19 Kube D, Rieth H, Eskdale J, Kremsner PG, Gallagher G. Structural characterisation of the distal 5' flanking region of the human interleukin-10 gene. Genes Immunity 2001;2:181-90.

20 Crawley E, Kay R, Sillibourne J, Patel P, Hutchinson I, Woo P. Polymorphic haplotypes of the interleukin-10 5' flanking region determine variable interleukin-10 transcription and are associated with particular phenotypes of juvenile rheumatoid arthritis. Arthritis Rheum 1999;42: $1101-8$

21 Turner D, Williams DM, Sankaran D, Lazarus M, Sinnott PJ, Hutchinson IV. An investigation of polymorphism in the interleukin-10 promoter. Eur J Immunogenet 1997;24:1-8.

22 Eskdale J, Gallagher G, Verweij CL, Keijsers V, Westendorp RGJ, Huizinga TWJ. Interleukin 10 secretion in relation to human IL-10 locus haplotypes. Proc Natl Acad Sci USA 1998;95:9465-70.

23 D'Alfonso S, Rampi M, Rolando V, Giordano M, Momigliano-Richiardi P. New polymorphisms in the IL-10 promoter region. Genes Immunity 2000;1:231-3.

24 Price P, Witt C, Allcock R, Sayer D, Garlepp M, Kok CC, French M, Mallal S, Christiansen F. The genetic basis for the association of the 8.1 ancestral haplotype (A1, B8, DR3) with multiple immunopathological diseases. Immunol Rev 1999;167:257-74

25 Hajeer AH, Hutchinson IV. Influence of TNFalpha gene polymorphisms on TNFalpha production and disease. Hum Immunol 2001;62:1 191-9.

26 D'Alfonso S, Rampi M, Bocchio D, Colombo G, Scorza-Smeraldi R, Momigliano-Richardi P. Systemic lupus erythematosus candidate genes in the Italian population: evidence for a significant association with interleukin-10. Arthritis Rheum 2000;43:120-8.

27 Helminen M, Lahdenpohja N, Hurme M. Polymorphism of the interleukin-10 gene is associated with susceptibility to Epstein-Barr virus infection. J Infect Dis $1999 ; 180: 496-9$

28 Wu MS, Huang SP, Chang YT, Shun CT, Chang MC, Lin MT, Wang HP, Lin JT. Tumor necrosis factor-alpha and interleukin-10 promoter polymorphisms in Epstein-Barr virus-associated gastric carcinoma. J Infect Dis 2002; 185: 106-9

29 Howell WM, Turner SJ, Bateman AC, Theaker JM. IL-10 promoter polymorphisms influence tumour development in cutaneous malignant melanoma. Genes Immunity 2001;2:25-31

30 Hajeer AH, Lazarus M, Turner D, Mageed RA, Vencovsky J, Sinnott P, Hutchinson IV, Ollier WE. IL-10 gene promoter polymorphisms in rheumatoid arthritis. Scand J Rheumatol 1998:27:142-5.

31 Tagore A, Gonsalkorale WM, Pravica V, Hajeer AH, McMahon R, Whorwell PJ, Sinnott PJ, Hutchinson IV. Interleukin-10 (IL-10) genotypes in inflammatory bowel disease. Tissue Antigens 1999;54:386-90.

32 Huizinga TW, Keijsers V, Yanni G, Hall M, Ramage W, Lanchbury J, Pitzalis C, Drossaers-Bakker WK, Westendorp RG, Breedveld FC, Panay $G$, Verweij CL. Are differences in interleukin 10 production associated with joint damage? Rheumatology 2000;39: 11 80-8.

33 Girndt M, Kaul H, Sester U, Ulrich C, Sester M, Georg T, Kohler H. Anti-inflammatory interleukin-10 genotype protects dialysis patients from cardiovascular events. Kidney Int 2002:62:949-55.

34 Shoskes DA, Albakri Q, Thomas K, Cook D. Cytokine polymorphisms in men with chronic prostatitis/chronic pelvic pain syndrome: association with diagnosis and treatment response. J Urol 2002;168:331-5.

35 Lio D, Licastro F, Scola L, Chiappelli M, Grimaldi LM, Crivello A, Colonna-Romano G, Candore G, Franceschi C, Caruso C. Interleukin-10 promoter polymorphism in sporadic Alzheimer's disease. Genes Immunity (in press).
36 Reynard MP, Turner D, Navarrete CV. Allele frequencies of polymorphisms of the tumour necrosis factor- $\alpha$, interleukin-10, interferon- $\gamma$ and interleukin-2 genes in a North European Caucasoid group from the UK. Eur J Immunogenet 2000;27:241-9.

37 Witte JS, Palmer L, O'Connor RD, Hopkins PJ, Hall JM. Relation between tumour necrosis factor polymorphism TNFalpha-308 and risk of asthma. Eur J Hum Genet 2002;10:82-5.

38 Sakao S, Tatsumi K, Igari $H$, Watanabe R, Shino $Y$, Shirasawa $H_{\text {, }}$ Kuriyama T. Association of tumor necrosis factor-alpha gene promoter polymorphism with low attenuation areas on high-resolution $\mathrm{CT}$ in patients with COPD. Chest 2002;122:416-20.

39 Dalziel B, Gosby AK, Richman RM, Bryson JM, Caterson ID. Association of the TNF-alpha $-308 \mathrm{G} / \mathrm{A}$ promoter polymorphism with insulin resistance in obesity. Obes Res 2002;10:401-7.

40 O'Keefe GE, Hybki DL, Munford RS. The G $\rightarrow$ A single nucleotide polymorphism at the -308 position in the tumor necrosis factor-alpha promoter increases the risk for severe sepsis after trauma. J Trauma 2002;52:817-25

41 Fernandes $\mathbf{H}$, Koneru $B$, Fernandes $N$, Hameed $M$, Cohen $M C$ Raveche $E$, Cohen $S$. Investigation of promoter polymorphisms in the tumor necrosis factor-alpha and interleukin-10 genes in liver transplant patients. Transplantation 2002;73:1886-91.

42 Heijmans BT, Westendorp RG, Droog S, Kluft C, Knook DL, Slagboom $\mathrm{PE}$. Association of the tumour necrosis factor alpha -308G/A polymorphism with the risk of diabetes in an elderly population-based cohort. Genes Immunity 2002;3:225-8.

43 van Dissel JT, van Langevelde P, Westendorp RGJ, Kwappenberg K, Frolich M. Anti-inflammatory cytokine profile and mortality in febrile patients. Lancet 1998;351:950-3.

44 Franceschi C, Bonafe $M$, Valensin S, Olivieri F, De Luca M, Ottaviani E, De Benedictis $G$. Inflamm-aging. An evolutionary perspective on immunosenescence. Ann NY Acad Sci 2000;908:244-54.

45 Franceschi C, Valensin S, Lescai F, Olivieri F, Licastro F, Grimaldi LM, Monti D, De Benedictis G, Bonafe M. Neuroinflammation and the genetics of Alzheimer's disease: the search for a pro-inflammatory phenotype. Aging 2001;13:163-70.

46 McCusker SM, Curran MD, Dynan KB, McCullagh CD, Urquhart DD Middleton D, Patterson CC, Mcllroy SP, Passmore AP. Association between polymorphism in regulatory region of gene encoding tumour necrosis factor alpha and risk of Alzheimer's disease and vascular dementia: a case-control study. Lancet 2001;357:436-9.

47 Wang XY, Hurme $M$, Jylha $M$, Hervonen A. Lack of association between human longevity and polymorphisms of IL-1 cluster, IL-6, IL-10 and TNF-alpha genes in Finnish nonagenarians. Mech Ageing Dev 2001;123:29-38.

48 Pes GM, Lio D, Carru C, Deiana L, Baggio G, Franceschi C, Ferrucci L, Olivieri F, Scola L, Crivello A, Candore G, Colonna-Romano G, Caruso C. Association between longevity and cytokine gene polymorphisms: a study in Sardinian centenarians. (Submitted).

49 Perneger TV. What's wrong with Bonferroni adjustments? BM 1998;316:1236-8.

50 Candore G, Colonna-Romano G, Lio D, Caruso C. Immunological and immunogenetic markers of successful and unsuccessful ageing. Adv Cell Aging Gerontol (in press). 